\title{
Additional Improvement of Stenosis Geometry in Human Coronary Arteries by Stenting After Balloon Dilatation
}

\author{
PATRICK W. SERRUYS, MD, YVES JUILLIERE, MD, MICHEL E. BERTRAND, MD, \\ JACQUES PUEL, MD, ANTHONY F. RICKARDS, MD, and ULRICH SIGWART, MD
}

The purpose of this study was to assess the early changes in stenosis geometry after insertion of intravascular stents in human coronary arteries. Morphologic changes were evaluated by quantitative coronary angiography (using automated edge detection) and by calculation of the theoretical pressure decrease across the dilated and stented stenosis from the Poiseuille and turbulent resistances assuming a coronary blood flow of either 1 or $3 \mathrm{ml} / \mathrm{s}$. Twentysix patients * were studied before and after angioplasty, as well as immediately after stent implanta- tion. The stented coronary artery was the left anterior descending artery in 19 cases, the circumflex artery in 2 cases, the right coronary artery in 2 cases and a coronary artery bypass vein graft in 3 cases. After stent implantation, an additional increase in minimal luminal cross-sectional area of the dilated vessel was observed, suggesting that the self-expanding stainless steel endoprosthesis used in this study has a dilating function in addition to its stenting role.

(Am J Cardiol 1988;61:71G-76G) ince the introduction of percutaneous transluminal coronary angioplasty in $1977,{ }^{1}$ continuing improvements in angioplasty technique have led to a high initial success rate and broad clinical applica. tion. ${ }^{2,3}$ However, the rate of restenosis during the first 6 months after the procedure is still high (30 to $40 \%)^{4-8}$; thus, restenosis remains one of the main limitations of this therapeutic procedure.

Intravascular stenting of the dilated vessels has been proposed as an alternative approach, along with other techniques-pharmacologic, ${ }^{6}$ mechanical ${ }^{9,10}$ and thermal ${ }^{11,12}$ - under investigation for preventing late restenosis. Different prostheses have been developed and tested in animal experiments, ${ }^{13-22}$ and re-

From the Catheterization Laboratory and Laboratory for Clinical and Experimental Image Processing, Thoraxcenter, Rotterdam, The Netherlands; Department of Cardiology, Hôpital Cardiologique, Lille, France; Department of Clinical Measurement, National Heart Institute, London, United Kingdom: Department of Clinical and Experimental Cardiology, CHRU Rangueil, Toulouse, France; and the Division of Cardiology, Department of Medicine, CHUV, Lausanne, Switzerland.

Address for reprints: Patrick W. Serruys, MD, PhD, Catheterization Laboratory and Laboratory for Clinical and Experimental Image Processing, Thoraxcenter, Erasmus University, P.O. Box 1738, 3000 DR Rotterdam, The Netherlands. cently in humans. ${ }^{20}$ The endoprosthesis used in this open clinical trial consists of a self-expanding stainless steel mesh (Medinvent, ${ }^{\circledR}$ ) that exerts an active radial force on the vascular wall after deployment. However, there is no quantitative angiographic data indicating whether this ongoing outward force affects the immediate anatomic result of balloon angioplasty.

The purpose of this study was to assess early morphologic changes in stenosis geometry by quantitative coronary angiography after stenting of human coronary arteries.

\section{Methods}

Patients: Twenty-six patients (20 men, 6 women) were studied. The patients were treated and investigated in the 5 following centers: Division of Cardiology, Department of Medicine, CHUV, Lausanne, Switzerland; Department of Clinical and Experimental Cardiology, CHRU Rangueil, Toulouse, France; Department of Cardiology, Hôpital Cardiologique, Lille, France; Department of Clinical Measurement, $\mathrm{Na}$ tional Heart Institute, London, United Kingdom; and the catheterization laboratory, Thoraxcenter, Rotterdam, The Netherlands. The endoprosthesis used in this study was provided by Medinvent SA, and inserted as previously described. ${ }^{20}$ The dilated and stented

${ }^{\star}$ Published in part in: Am J Cardiol 1988;61:546-553. 
. 
coronary artery was the left anterior descending artery in 19 cases, the circumflex artery in 2 cases, the right coronary artery in 2 cases and a coronary artery bypass vein graft in 3 cases. Each patient gave informed consent before the intervention.

Description of the stent: The stent is woven from a surgical grade stainless steel alloy formulated according to the specifications of the International Standards Organization. The prosthesis is geometrically stable, pliable and self-expanding, consisting of 16 wire filaments, each $0.08 \mathrm{~mm}$ in diameter (Fig. 1). Its elastic and pliable properties are such that its diameter can be substantially reduced by moderate elongation. It can be constrained on a small-diameter delivery catheter, but spontaneously returns to its original (unconstrained) larger diameter when the constraining mem-
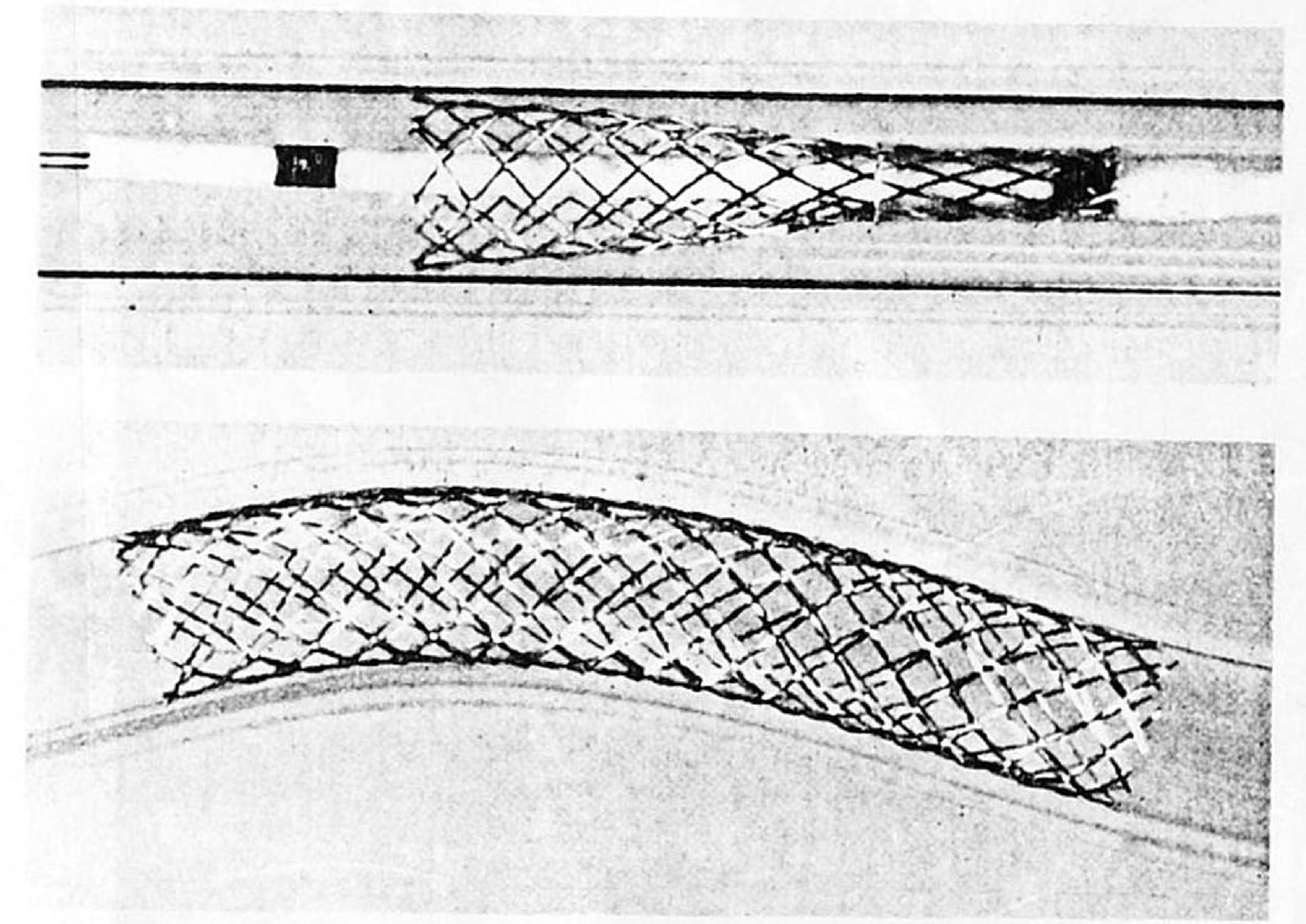

FIGURE 1. Top, simulated implantation in a length of plastic tube. A doubled-over membrane maintains the stent constrained in an elongated state. Retraction of this membrane allows the stent to be progressively released into the vascular lumen. In doing so, the stent gradually shortens and expands. Bottom, implanted stent within curvature of plastic tube, demonstrating the stent's pliability. brane is progressively removed (Fig. 2). The outer diameter of the stent-catheter system mounted on this delivery device is $1.57 \mathrm{~mm}$, using prostheses that expanded to a diameter of $6.5 \mathrm{~mm}$. In this study, the unconstrained stent diameter ranged from 3.0 to 5.0 $\mathrm{mm}$. The stent sizes were selected based on the size of the arterial segment, taking into account that the stent in its unconstrained form must have a diameter $0.5 \mathrm{~mm}$ larger than the stented vessel.

Quantitative coronary angiography: The determination of coronary arterial dimensions from $35 \mathrm{~mm}$ cinefilm was performed with the computer-based Cardiovascular Angiography Analysis System, previously described in detail. ${ }^{23-25}$ In essence, boundaries of the relevant coronary artery segment are detected automatically from optically magnified and video-digitized regions of interest of a selected cineframe (Fig. 3). The absolute diameter of the stenosis in millimeters is determined by comparison to the known diameter of the guiding catheter. This involves the automated edgedetection of its boundaries in situ and the comparison of this value with the actual diameter measurement of the catheter. Determination of the stenosis diameter in absolute values $(\mathrm{mm})$ is achieved by comparing its mean diameter to that of the guiding catheter. To correct the detected contours of the arterial and catheter segments for pincushion distortion, a correction vector is computed for each pixel based on a computer-processed cineframe of a centimeter grid placed against the input screen of the image intensifier. ${ }^{23}$ Since the functional significance of a stenosis is related to the expected normal cross-sectional area of the vessel at the point of obstruction, we used a computer estimation of the original arterial dimension at the site of the obstruction to define the interpolated reference region. ${ }^{23,24}$ The interpolated percentage area stenosis and the minimal luminal cross-sectional area $\left(\mathrm{mm}^{2}\right)$ are then calculated from, at least 2, preferably orthogonal projections. The length of the lesion is determined from the diameter function on the basis of a curvature analysis.
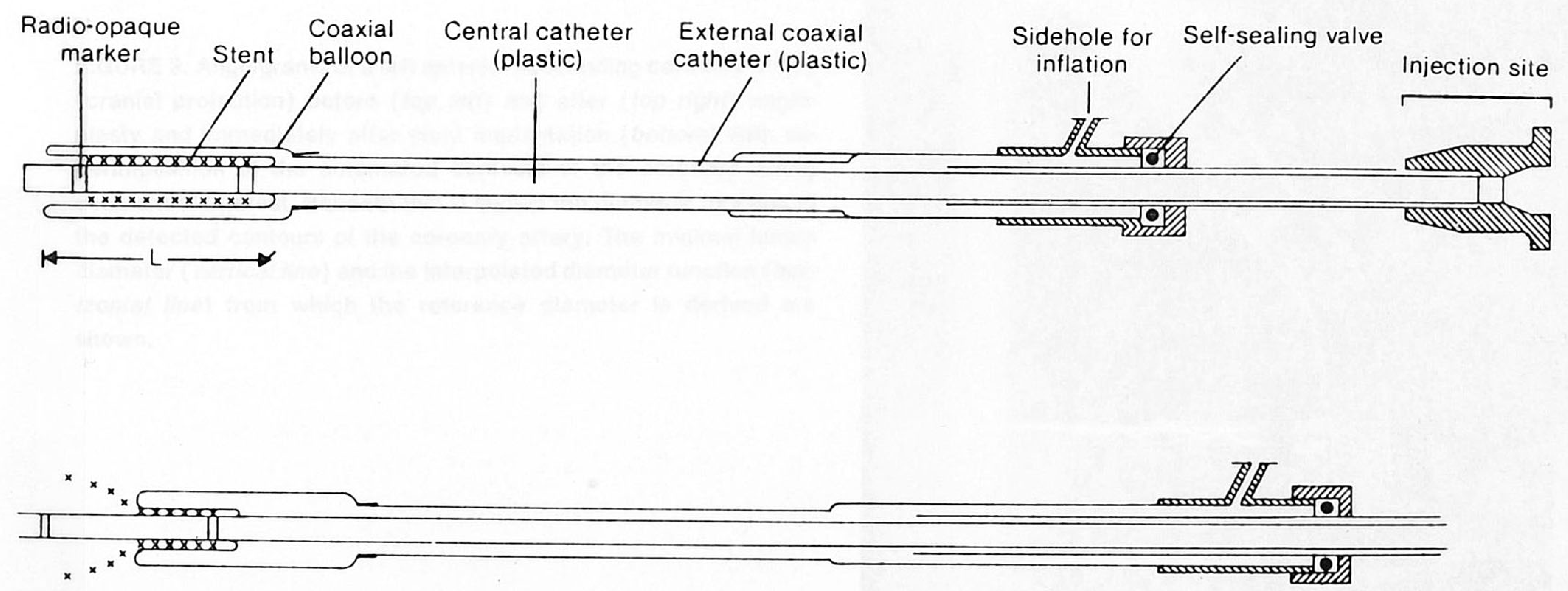

The accuracy of this quantification method has previously been validated with Plexiglas ${ }^{\circledR}$ phantoms filled with contrast medium (perspex models). ${ }^{26}$ The overall accuracy (average difference) and precision (pooled standard deviation of the differences) of our contour detection technique for the measurement of percentage diameter stenosis are 2.00 and $2.68 \%$, respectively, and for the measurement of obstruction diameters, -30 and $+90 \mu$, respectively. The mean differences \pm standard deviations of the differences in the obstruction and interpolated reference diameters, as well as in the interpolated percentage diameter stenosis, have previously been published for short-term ( 5 minutes), medium-term (60 minutes) and long-term (90 days) studies. The variability in obstruction diameter for these 3 types of studies ranged from $0.22 \mathrm{~mm}$ for the medium-term study to $0.36 \mathrm{~mm}$ for the least well-controlled long-term study. In the long-term study group, the lack of significant variation in the mean difference of the minimal lumen diameters suggests that no detectable progression or regression of atherosclerotic lesions occurred over the period of 90 days. Therefore, a change greater than the total measurement variability of repeated coronary cineangiography and quantitative analysis $(0.36 \mathrm{~mm}$ for obstruction diameter, i.e., 1 standard deviation of difference of duplicate measure-
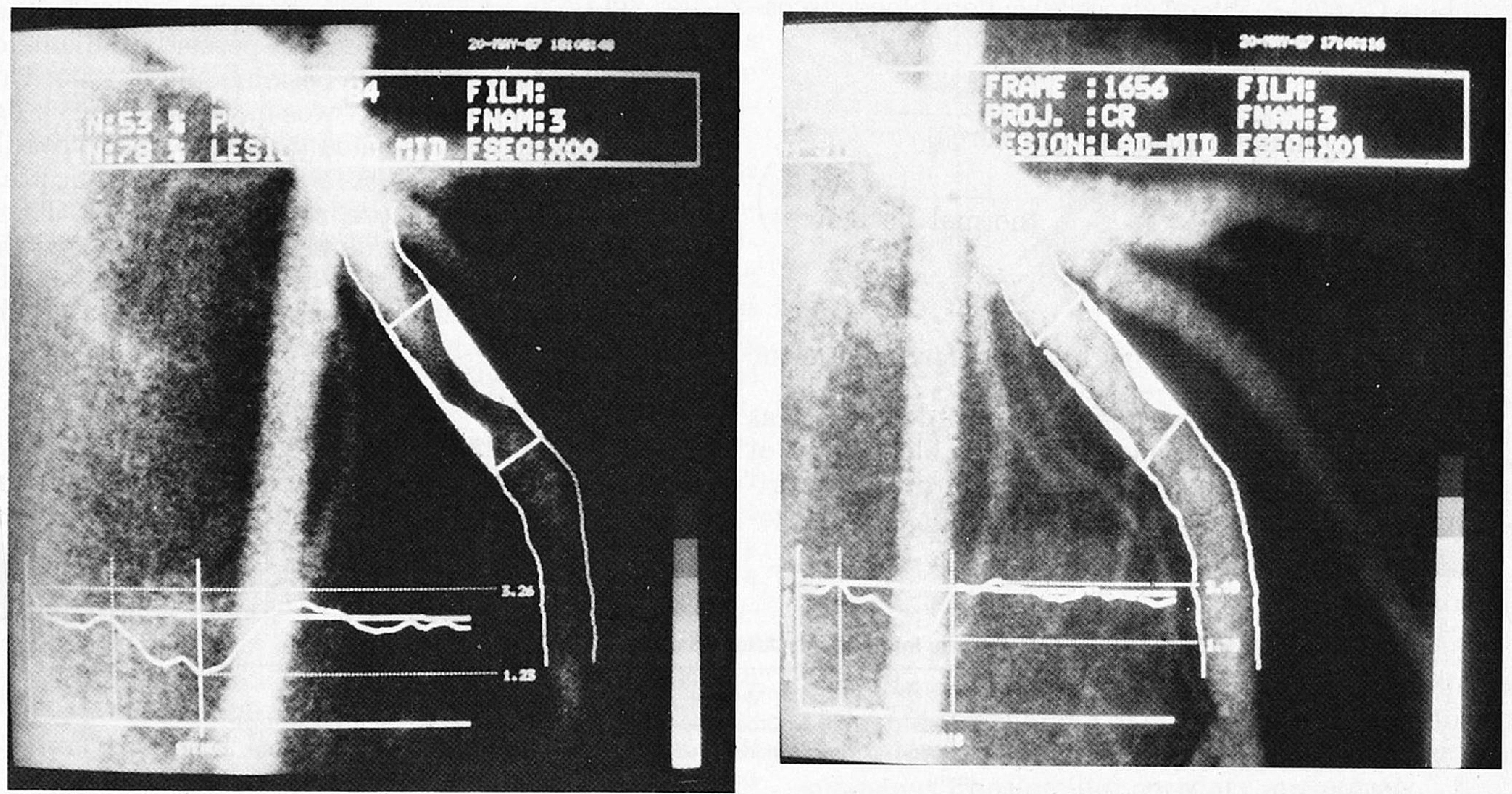

FIGURE 3. Angiograms of a left anterior descending coronary artery (cranial projection) before (top left) and after (top right) angioplasty and immediately after stent implantation (bottom) with superimposition of the automated contours of the coronary artery segment of interest. Beneath this is shown the diameter function of the detected contours of the coronary artery. The minimal lumen diameter (vertical line) and the interpolated diameter function (horizontal line) from which the reference diameter is derived are shown.

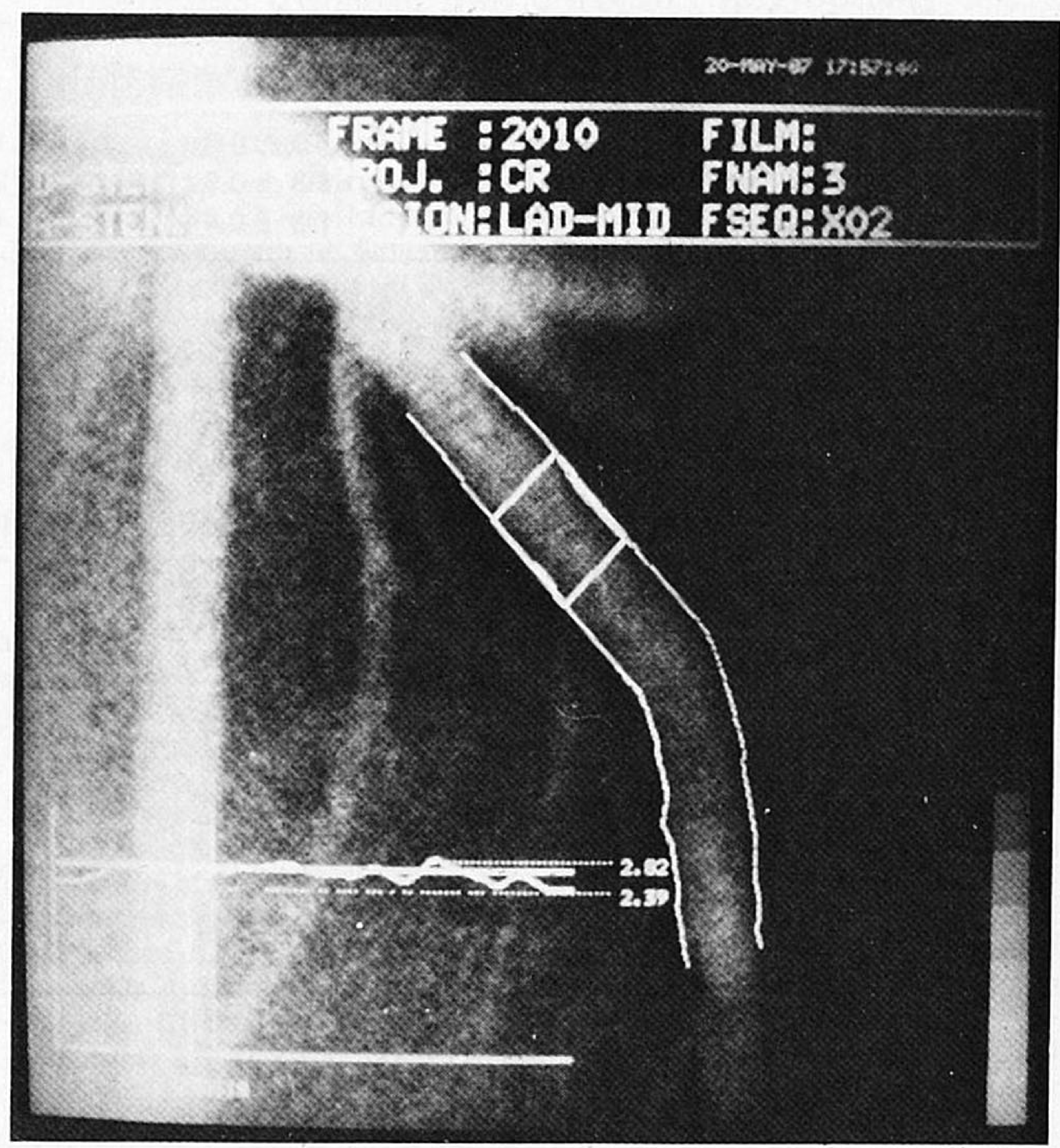


ments) was considered significant and indicative of restenosis. This change in absolute values corresponds to a change of $6.5 \%$ in percentage diameter stenosis. ${ }^{24}$

Hemodynamic assessment: The theoretical pressure decrease was calculated using the arteriogram and digtial computation, according to the well-known formulas described in the literature ${ }^{27,28}$ : Pgrad $=\mathrm{Q}$. $(\mathrm{Rp}+\mathrm{Q} \cdot \mathrm{Rt})$, where Pgrad is the theoretical transstenotic pressure decrease ( $\mathrm{mm} \mathrm{Hg}$ ) over the stenosis, Q the mean coronary blood flow (ml/s), Rp the Poiseuille resistance and $\mathrm{Rt}$ the turbulent resistance.

These resistances have been defined as follows:

$$
\mathrm{Rp}=\mathrm{C}_{1} \cdot \frac{(\text { length obstruction) }}{(\text { minimal cross-sectional area })^{2}}
$$

where $\mathrm{C}_{1}=8 \cdot \pi \cdot($ blood viscosity); where blood viscosity $=0.03 \mathrm{~g} / \mathrm{cm} \cdot \mathrm{s}$

$$
\mathrm{Rt}=\mathrm{C}_{2} \cdot\left(\frac{1}{(\text { minimal cross-sectional area })}-\right.
$$$$
\left.\frac{1}{(\text { normal distal area })}\right)^{2}
$$

where $\mathrm{C}_{2}=\frac{\text { (blood density) }}{0.266}$;

$$
\text { where blood density }=1.0 \mathrm{~g} / \mathrm{cm}^{3}
$$

The theoretical transstenotic pressure decrease was calculated for a theoretical coronary blood flow of $0.5,1$ and $3 \mathrm{ml} / \mathrm{s}$. The Poiseuille and turbulent contributions to flow resistance were determined from ste- nosis geometry assessed by quantitative coronary angiography.

Statistical analysis: Comparisons between measurements obtained after PTCA and stenting were performed using the Student $t$ test for paired observations.

\section{Results}

Twenty-six patients were studied and a mean of 1.6 \pm 0.5 angiographic projections per lesion was analyzed (Fig. 3). The morphologic and hemodynamic data (mean \pm standard error of the mean as well as the individual values of the parameters for each patient) are presented in Tables I and II, respectively.

Stent implantation after angioplasty resulted in an additional increase in minimal luminal cross-sectional area (Fig. 4) and obstruction diameter, and a further decrease in percentage area and percentage diameter stenosis compared with the postangioplasty state. This morphologic improvement was associated with a decrease in both the calculated turbulent and Poiseuille resistance, as well as the theoretical transstenotic pressure decrease for a theoretical flow of $1 \mathrm{ml} / \mathrm{s}$. These data suggest that immediately after angioplasty, the endoprosthesis has an active dilating function in addition to its basic stenting (maintainence of dilated diameter) role.

\section{Discussion}

Although initial success rates for coronary angioplasty have improved, the problem of restenosis con-

\begin{tabular}{|c|c|c|c|c|}
\hline & $\begin{array}{c}\text { Extent } \\
\text { Obstruction } \\
(\mathrm{mm})\end{array}$ & $\begin{array}{c}\text { Minimal } \\
\text { Cross-Sec- } \\
\text { tional Area } \\
\left(\mathrm{mm}^{2}\right)\end{array}$ & $\begin{array}{c}\text { Percentage } \\
\text { Area } \\
\text { Stenosis } \\
(\%)\end{array}$ & $\begin{array}{c}\text { Reference } \\
\text { Area } \\
\left(\mathrm{mm}^{2}\right)\end{array}$ \\
\hline \multicolumn{5}{|l|}{$\begin{array}{l}\text { Mean } \\
\pm S D\end{array}$} \\
\hline Pre-P & $\Gamma \quad 7.5 \pm 0.5$ & $\Gamma 1.2 \pm 0.2$ & $\lceil 81 \pm 2$ & $\Gamma_{7.3} \pm 0.7$ \\
\hline Post-P & ᄂ $6.9 \pm 0.5$ N & $\lfloor 2.9 \pm 0.2]$ & {$[55 \pm 2 ?$} & NS $7.2 \pm 0.7$ \\
\hline Post-S & $7.3 \pm 0.4$ & $4.8 \pm 0.5\rfloor$ & $36 \pm 3$ & $7.7 \pm 0.7$ \\
\hline
\end{tabular}
tinues to compromise the overall results of the pro-

TABLE I Morphologic Results Immediately After Stenting

\begin{tabular}{|c|c|c|c|c|c|}
\hline & \multirow[b]{2}{*}{$\begin{array}{c}\text { Poiseuille } \\
\text { Resistance } \\
\text { (dynes } \mathrm{cm}^{-5} \text { ) }\end{array}$} & \multirow[b]{2}{*}{$\begin{array}{c}\text { Turbulent } \\
\text { Resistance } \\
\text { (dynes } \mathrm{sm}^{-5} \text { ) }\end{array}$} & \multicolumn{3}{|c|}{ Pressure Gradient (mm Hg) } \\
\hline & & & $\begin{array}{c}\text { Flow } \\
(0.5 \mathrm{ml} / \mathrm{s})\end{array}$ & $\begin{array}{c}\text { Flow } \\
(1 \mathrm{ml} / \mathrm{s})\end{array}$ & $\begin{array}{c}\text { Flow } \\
(3 \mathrm{ml} / \mathrm{s})\end{array}$ \\
\hline \multicolumn{6}{|l|}{$\begin{array}{l}\text { Mean } \\
\pm S D\end{array}$} \\
\hline Pre-P & $31.3 \pm 21.2$ & $20.1 \pm 14.2$ & $\lceil 6.6 \pm 1.7$ & $\Gamma 16.3 \pm 4.3$ & $\lceil 29.3 \pm 7.1$ \\
\hline Post-P & $0.7 \pm 0.1 ?$ & $0.1 \pm 0.0 ?$ & $\lfloor 3.0 \pm 0.0]$ & $\lfloor 1.8 \pm 0.1]$ & $\lfloor 3.2 \pm 0.4$ ? \\
\hline Post-S & $0.3 \pm 0.0$ & $0.0 \pm 0.0$ & $0.1 \pm 0.0$ & $0.3 \pm 0.1\rfloor$ & $1.1 \pm 0.2\rfloor$ \\
\hline
\end{tabular}

TABLE II Hemodynamic Results Immediately After Stenting 
cedure. ${ }^{29}$ With restenosis rates ranging from 30 to $40 \%, 4,5,7,9$ there is an evident need for new techniques to prevent restenosis.

A promising new approach to reduce the rate of restenosis and help prevent abrupt reclosure is the implantation of an intravascular endoprosthesis. The principle of introducing intraarterial grafts percutaneously was first described by Dotter in $1969 .{ }^{14}$ Over the last few years, variants of the original technique using thermal-shaped memory alloy, ${ }^{13,21,29}$ expanding spring steel spirals, ${ }^{21}$ expanding stainless steel stents ${ }^{27,30}$ and expanding woven stainless steel meshes ${ }^{16,18,19}$ have been reported in animal experiments.

Recently, intravascular stents have been implanted in humans to prevent occlusion and restenosis after transluminal angioplasty. ${ }^{20}$ The endoprosthesis used in this first clinical series consisted of a new self-expandable stainless steel mesh. The present study has used quantitative coronary angiography to assess the early modifications in stenosis geometry after implantation of this new endoprosthesis.

The early assessment immediately after stent implantation shows an additional morphologic improvement over results after balloon dilatation, demonstrating the intrinsic dilating force exerted by the stent. The problems arising with expandable vascular protheses are whether a stable positioning can be achieved only by expansile pressure against the vessel wall, and what are the pressure thresholds to avoid serious injury such as vessel-wall pressure necrosis. Using an intravascular "double-helix" spiral prosthesis, Maass et $\mathrm{al}^{30}$ showed that the preimplantation calculation of the fixation pressure can be estimated if the elasticity module of the material, the thickness of the metal wire and the radii of the unconstrained as well as the partially expanded spiral prosthesis are known. Their experiments in dogs indicate that pressures up to $300 \mathrm{~mm}$ $\mathrm{Hg}$ are well tolerated in the volume as well as in the arterial system. In the former, however, this may represent an upper limit, whereas in the arterial system, a higher pressure probably can be sustained. Perforation, deep pressure marks or cutting effects of the spiral coils were observed only in pressures exceeding $3,000 \mathrm{~mm} \mathrm{Hg}$. Sigwart et al ${ }^{20}$ also indicated that this prosthesis has an elastic radial force that tends to dilate the artery when the vessel caliber is less than that of unconstrained stent diameter. Dilatation continues until an equilibrium is attained between the circumferential elastic resistance of the arterial wall and the dilating force of the prosthesis. Previously, Wright and Wallace ${ }^{31}$ showed that the expansile pressure depends on the recipient vessel diameter and on the intrinsic dilating force of the stent itself. The present study confirms the dilating capacity of the stent in human beings.

\section{Conclusion}

Percutaneous implantation of the self-expandable stainless steel endoprosthesis is a new technique to prevent restenosis after human coronary angioplasty. The dilating radial force of the stent is responsible for an additional improvement in the results of angio-

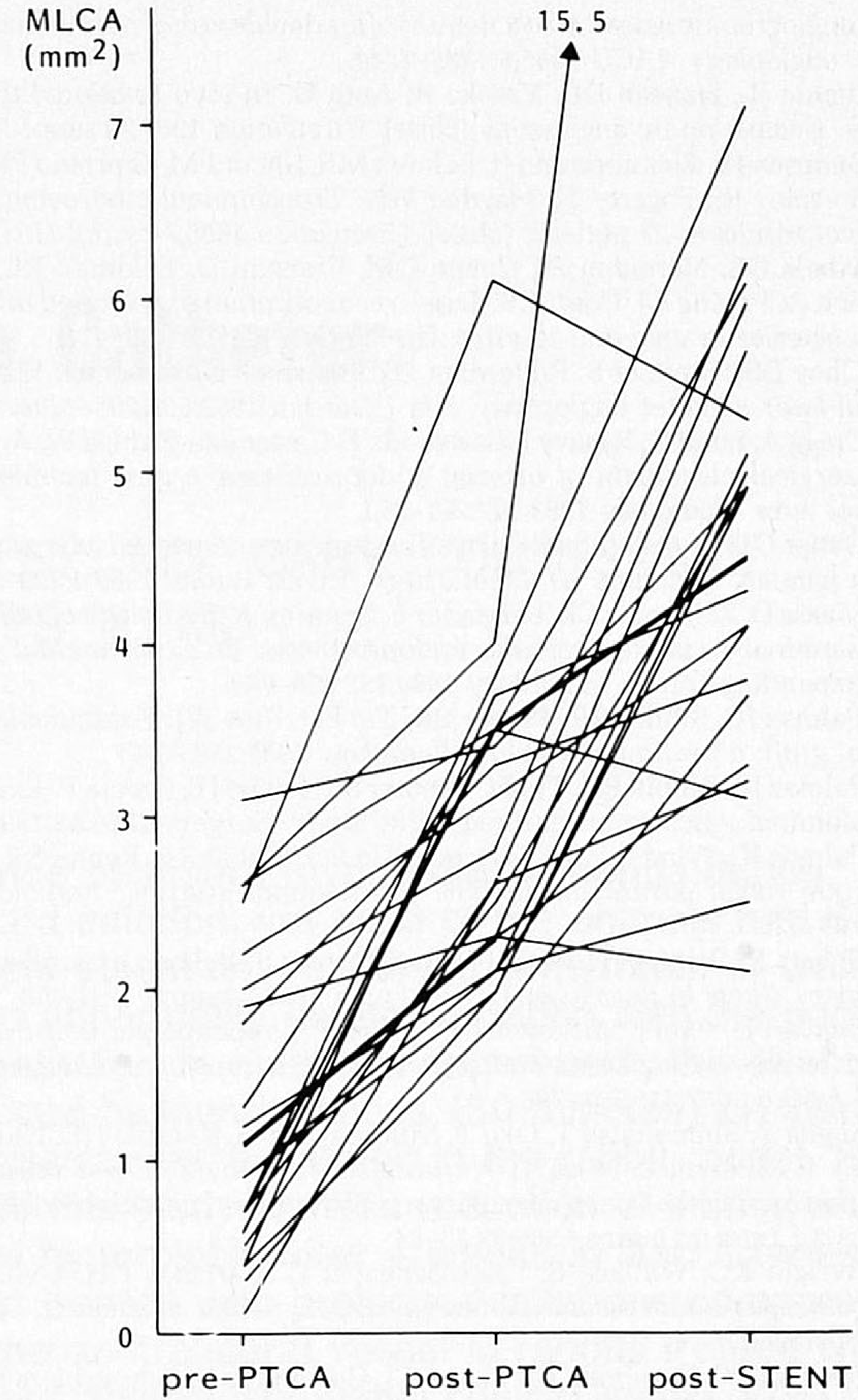

FIGURE 4. Changes in minimal luminal cross-sectional area (MLCA) between percutaneous transluminal coronary angioplasty before (pre-PTCA), after (post-PTCA) and immediately after stent (post-STENT) implantation.

plasty. Intravascular stenting may be a promising complementary technique to coronary angioplasty to prevent abrupt closure and late restenosis after percutaneous transluminal coronary angioplasty.

\section{References}

1. Gruentzig AR, Senning A, Siegenthaler WE. Nonoperative dilatation of coronary artery stenosis. N Engl I Med 1979;301:61-68.

2. Dorros G, Cowley MJ, Simpson J, Bentivoglio LG, Block PC, Bourassa M, Detre K, Gosselin AJ, Gruentzig AR, Kelsey SF, Kent KM, Mock MB, Mullin SM, Myler RK, Passamani ER, Stertzer SH, Williams DO. Percutaneous transluminal coronary angioplasty: report of complications from the National Heart, Lung and Blood Institute PTCA Registry. Circulation 1983;67:723-730. 3. Faxon DP, Kelsey SF, Ryan TJ, McCabe CH, Detre K. Determinants of successful percutaneous transluminal coronary angioplasty: report from the NHLBI Registry. Am Heart I 1984;108:1019-1023.

4. Bertrand ME, Marco J, Cherrier F, Schmitt R, Gaspard P, Puel J, Valeix B, Bory M, Crochet H, Geschwind H, Berland R, Machecourt J, Foucault JP, Bassand JP, Bourdonnec C, Quiret A, Jault F. French percutaneous transluminal coronary angioplasty (PTCA) registry: four years experience (abstr). IACC 1986;7:21A.

5. Holmes DR Jr, Vliestra RE, Smith HC, Vetrovec GW, Kent KM, Cowley MJ, Maxon DP, Gruentzig AR, Kelsey SF, Detre KM, van Raden MJ, Mock DB. Restenosis after percutaneous transluminal coronary angioplasty (PTCA): a report from the PTCA registry of the NHLBI. Am I Cardiol 1984;53:77C-81C. 6. Leimgruber PP, Roubin GS, Hollman J, Cotsonis GA, Meier B, Douglas JS, King SB III, Gruentzig AR. Restenosis after successful coronary angioplasty in patients with single-vessel disease. Circulation 1986;73:710-717.

7. Mabin TA, Holmes DR Jr, Smith HC, Vliestra RE, Reeder GS, Bresnahan JF, Bove AA, Hammes LN, Elveback LR, Orszulak TA. Follow-up clinical results in patients undergoing percutaneous transluminal coronary angioplasty. Circulation 1985;71:754-760.

8. Mata LA, Bosch X, David PR, Kapold HJ, Corcos T, Bourassa MG. Clinical 
and angiographic assessment 6 months after double vessel percutaneous coronary angioplasty. JACC 1985;6:1239-1244.

9. Ritchie JL, Hansen DD, Vracko R, Auth D. In vivo rotational thrombectomy. Evaluation by angioscopy (abstr). Circulation 1986;74:suppl II:II-457. 10. Simpson JB, Zimmermann JJ, Selmon MR, Shoor PM, Cipriano PR, Martin F. McAuley BJ. Fogarty TJ, Hayden WG. Transluminal atherectomy: initial clinical results in 27 patients (abstr). Circulation 1986;74:suppl II:II-203.

11. Abela GS, Normann SJ, Cohen DM, Franzini D, Feldman RL, Crea F, Fenech A, Pepine CJ, Conti CR. Laser recanalization of occluded atherosclerotic arteries in vivo and in vitro. Circulation 1985;71:403-411.

12. Choy DSJ, Stertzer S, Rotterdam HZ, Sharrock N, Kaminow IP. Transluminal laser catheter angioplasty. Am I Cardiol 1982;50:1206-1208.

13. Cragg A, Lund G, Rysavy J, Castenada F, Castenada-Zuniga W, Amplatz K. Nonsurgical placement of arterial endoprostheses: a new technique using nitinol wire. Radiology 1983;147:261-263

14. Dotter CT. Transluminally placed coil-spring endarterial tube grafts: longterm patency in canine popliteal artery. Invest Radiol 1969;4:329-332.

15. Maass D, Zollikofer CL, Largiader F, Senning A. Radiological follow-up of transluminally inserted vascular endoprostheses: an experimental study using expanding spirals. Radiology 1984;152:659-663.

16. Palmaz JC, Sibbitt RR, Reuter SR, Tio FO, Rice WJ. Expandable intraluminal graft: a preliminary study. Radiology 1985;156:73-77.

17. Palmaz JC, Sibbitt RR, Tio FO, Reuter SR, Peters JE, Garcia F. Expandable intraluminal vascular graft: a feasibility study. Surgery 1986;99:199-205. 18. Palmaz JC, Windeler SA, Garcia F, Tio FO, Sibbitt RR, Reuter SR. Atherosclerotic rabbit aortas: expandable intraluminal grafting. Radiology 1986; 160:723-726.

19. Schatz R, Palmaz J, Garcia F, Tio F, Reuter S. Balloon expandable intracoronary stents in dogs (abstr). Circulation 1986;74:suppl II:II-458.

20. Sigwart U, Puel J, Mirkowitch V, Joffre F, Kappenberger L. Intravascular stents to prevent occlusion and restenosis after transluminal angioplasty. $N$ Engl I Med 1987;316:701-706.

21. Sugita Y, Shimomitsu T, Oku T, Murabayashi S, Kambic HE, Harasaki H, Shirey E, Golding L, Nosé Y. Nonsurgical implantation of a vascular ring prosthesis using thermal shape memory $\mathrm{Ti} / \mathrm{Ni}$ Alloy (nitinol wire). Trans $\mathrm{Am}$ Soc Artif Intern Organs 1986;32:30-34

22. Wright KC, Wallace S, Charnsangavej C, Carrasco CH, Gianturco C. Percutaneous endovascular stents: an experimental evaluation. Radiology 1985;156:69-72.

23. Reiber JHC, Kooijman CJ, Slager CJ, Gerbrands JJ, Schuurbiers JHC, den Boer A, Wijns W, Serruys PW, Hugenholtz PG. Coronary artery dimensions from cineangiograms; methodology and validation of a computer-assisted analysis procedure. IEEE Trans Med Imaging 1984;3:131-141.

24. Reiber JHC, Serruys PW, Kooijman CJ, Wijns W, Slager CJ, Gerbrands JJ, Schuurbiers JHC, den Boer A, Hugenholtz PG. Assessment of short-, mediumand long-term variations in arterial dimensions from computer-assisted quantification of coronary cineangiograms. Circulation 1985;71:280-288.

25. Zijlstra F, van Ommeren J, Reiber JHC, Serruys PW. Does quantitative assessment of coronary artery dimensions predict the physiological significance of a coronary stenosis? Circulation 1987;75:1154-1161.

26. Reiber JHC, Serruys PW, Slager CJ. Quantitative coronary and left ventricular cineangiography. Methodology and clinical applications. Dordrecht: Martinus Nijhoff, 1986:116-139.

27. Brown BG, Bolson E, Frimer M, Dodge HT. Quantitative coronary arteriography. Estimation of dimensions, hemodynamic resistance and atheroma mass of coronary artery lesions using the arteriogram and digital computation. Circulation 1977;55:329-337.

28. Gould KL, Kelley KO, Bolson EL. Experimental validation of the quantitative coronary arteriography for determining pressure-flow characteristics of coronary stenosis. Circulation 1982;66:930-937.

29. Dotter CT, Bushmann RW, McKinney MK, Rösch J. Transluminal expandable nitinol coil stent grafting: preliminary report. Radiology 1983; 147:259-260.

30. Maass D, Kropf L, Egloff L, Demierre D, Turina M, Senning A. Transluminal implantation of intravascular "double-helix" spiral prostheses: technical and biological considerations. Proc Eur Soc Artif Organs 1982;9:252-256. 31. Lawrence DD, Charnsangavej C, Wright KC, Gianturco C, Wallace S. Percutaneous endovascular graft: experimental evaluation. Radiology 1987; 163:357-360.

\section{Appendix}

Participating Centers and Collaborators: Catheterization laboratory for clinical and experimental image processing, Thoraxcenter, Rotterdam, The Netherlands: M. v.d. Brand, MD, P. J. de Feyter, MD, P. G. Hugenholtz, MD, Y. Jullière, MD, J. H. C. Reiber, PhD, J. R. T. C. Roelandt, MD, P. W. Serruys, MD; Department of Cardiology, Hôpital Cardiologique, Lille, France: M. E. Bertrand, MD, J. M. Lablanche, MD; Department of Clinical Measurement, National Heart Institute, London, United Kingdom: A. F. Rickards, MD, P. Urban, MD; Department of Clinical and Experimental Cardiology, CHRU Rangueil, Toulouse, France: J. P. Bounhoure, MD, A. Courtault, MD, F. Joffre, MD, J. Puel, MD, H. Rousseau, MD; Division of Cardiology, Department of Medicine, CHUV, Lausanne, Switzerland: L. Kappenberger, MD, U. Sigwart, MD. 